Keywords: relapsed neuroblastoma; epidemiology; post-relapse progression-free survival; post-relapse overall survival; high risk; intermediate risk

\title{
Factors associated with recurrence and survival length following relapse in patients with neuroblastoma
}

\author{
Nermine O Basta ${ }^{1}$, Gail C Halliday ${ }^{2,3}$, Guy Makin ${ }^{4,5}$, Jillian Birch ${ }^{4}$, Richard Feltbower ${ }^{6}$, Nick Bown ${ }^{7}$, \\ Martin Elliott ${ }^{8}$, Lucas Moreno9, Giuseppe Barone ${ }^{9}$, Andrew DJ Pearson ${ }^{9}$, Peter W James ${ }^{1}$, \\ Deborah A Tweddle ${ }^{\star, 2,3}$ and Richard JQ McNally ${ }^{\star, 1}$ \\ ${ }^{1}$ Institute of Health \& Society, Newcastle University, Newcastle upon Tyne, UK; ${ }^{2}$ Newcastle Cancer Centre at the Northern Institute \\ for Cancer Research, Newcastle University, Newcastle upon Tyne, UK; ${ }^{3}$ Department of Paediatric Oncology, The Great North \\ Children's Hospital, Newcastle upon Tyne, UK; ${ }^{4}$ Institute of Cancer Sciences, Manchester Cancer Research Centre, Manchester \\ Academic Health Sciences Centre, University of Manchester, Manchester, UK; ${ }^{5}$ Department of Paediatric Oncology, Royal \\ Manchester Children's Hospital, Manchester, UK; ${ }^{6}$ Division of Epidemiology and Biostatistics, School of Medicine, University of \\ Leeds, Leeds, UK; ${ }^{7}$ Institute of Genetic Medicine, Newcastle University, Newcastle upon Tyne, UK; ${ }^{8}$ Paediatric Oncology and \\ Haematology Department, Leeds Teaching Hospitals NHS Trust, Leeds, UK and ${ }^{9}$ Children and Young People's Unit, The Royal \\ Marsden NHS Foundation Trust, Sutton, and Division of Clinical Studies and Cancer Therapeutics, The Institute of Cancer \\ Research, Sutton, UK
}

Background: Despite therapeutic advances, survival following relapse for neuroblastoma patients remains poor. We investigated clinical and biological factors associated with length of progression-free and overall survival following relapse in UK neuroblastoma patients.

Methods: All cases of relapsed neuroblastoma, diagnosed during 1990-2010, were identified from four Paediatric Oncology principal treatment centres. Kaplan-Meier and Cox regression analyses were used to calculate post-relapse overall survival (PROS), post-relapse progression-free survival (PRPFS) between relapse and further progression, and to investigate influencing factors.

Results: One hundred eighty-nine cases were identified from case notes, 159 (84.0\%) high risk and 17 (9.0\%), unresectable, MYCN non-amplified (non-MNA) intermediate risk (IR). For high-risk patients diagnosed > 2000, median PROS was 8.4 months (interquartile range $(I Q R)=3.0-17.4)$ and median PRPFS was 4.7 months $(I Q R=2.1-7.1)$. For $I R$, unresectable non-MNA patients, median PROS was 11.8 months (IQR 9.0-51.6) and 5-year PROS was 24\% (95\% Cl 7-45\%). MYCN amplified (MNA) disease and bone marrow metastases at diagnosis were independently associated with worse PROS for high-risk cases. Eighty percent of high-risk relapses occurred within 2 years of diagnosis compared with 50\% of unresectable non-MNA IR disease.

Conclusions: Patients with relapsed HR neuroblastomas should be treatment stratified according to MYCN status and PRPFS should be the primary endpoint in early phase clinical trials. The failure to salvage the majority of IR neuroblastoma is concerning, supporting investigation of intensification of upfront treatment regimens in this group to determine whether their use would diminish likelihood of relapse.

*Correspondence: Professor DA Tweddle; E-mail: deborah.tweddle@newcastle.ac.uk or Dr RJQ McNally; E-mail: richard.mcnally@ncl.ac.uk Revised 11 July 2016; accepted 29 August 2016; published online 4 October 2016

(c) 2016 Cancer Research UK. All rights reserved 0007-0920/16 
Neuroblastoma, the second most common childhood solid tumour, accounts for $8 \%$ of all childhood (0-14 years) cancers in the United Kingdom (Stiller, 2007). It is one of the most difficult childhood cancers to cure with UK and Ireland 5-year survival of $64.7 \%$ for cases diagnosed during 2005-2007 (Gatta et al, 2014).

However, survival remains poor for children diagnosed with high-risk disease (50\% of all neuroblastoma) (Cohn et al, 2009) defined as stage $4>1$ year of age, or MYCN amplified (MNA) localised (stages 2 and 3 ) or MNA infant ( $<12$ month) disease, with relapse in $>50 \%$ of cases (Maris et al, 2007; Maris, 2010). Relapse also occurs in other risk groups including intermediate risk (around 20\% of cases at diagnosis) defined as MYCN nonamplified (non-MNA), unresectable (stage 3) and non-MNA stage $4<12$ months old cases. The presence of MNA is a wellestablished poor prognostic marker in patients with neuroblastoma with localized disease and infants $<12$ months of age (Cohn and Tweddle, 2004; Maris et al, 2007; Canete et al, 2009). Survival from relapsed high-risk neuroblastoma is currently $<10 \%$ (London et al, 2011; Park et al, 2013). The disease control intervals and the patterns of recurrence are important for evaluation of new treatment strategies and early phase study designs, as they are increasingly being used to define alternative end-points to tumour response (Santana et al, 2008; Fox et al, 2014).

Some recent studies have reported clinical features of relapsed neuroblastoma (Garaventa et al, 2009; London et al, 2011; Simon et al, 2011), however few report length of post-relapse progressionfree survival (PRPFS). The present study aimed to investigate factors associated with recurrence, survival length following relapse and length of progression-free survival in patients with neuroblastoma diagnosed and treated at four UK Paediatric Oncology principal treatment centres. This study included information from patient file review on PRPFS, which is essential for informing the design and judging the efficacy of new treatments tested in early phase clinical trials.

\section{MATERIALS AND METHODS}

Study patients. All cases of relapsed and refractory/progressive neuroblastoma diagnosed during 1990-2010 were identified from four UK Paediatric Oncology principal treatment centres (The Royal Victoria Infirmary, Newcastle, Leeds Teaching Hospitals NHS Trust, The Royal Manchester Children's Hospital and The Royal Marsden Hospital). Population-based data from three specialist registries were used: the Northern Region Young Persons' Malignant Disease Registry (NRYPMDR) (Cotterill et al, 2000), the Yorkshire Specialist Register of Cancer in Children and Young People (YSRCCYP) (Feltbower et al, 2004) and the Manchester Children's Tumour Registry (MCTR) (Birch, 1988), and a non-population database held at the Royal Marsden Hospital NHS Foundation Trust. All cases within the age ranges of the registries were included. Year 1990 was chosen as the start date as from this date onwards combination chemotherapy and high-dose myeloablative therapy were routinely used to treat high-risk neuroblastoma (Pritchard et al, 2005; Pearson et al, 2008). Nine patients who died within 7 days of relapse were excluded as their survival and treatment data at relapse would be limited.

Definition of relapse. The International Neuroblastoma Response Classification (INRC) criteria were used to define relapse as a new site of disease or $25 \%$ increase in tumour size following an initial response (including partial) to treatment, and refractory disease as tumours that did not respond to any first-, second- or third-line therapies and subsequently progressed (Brodeur et al, 1993).

Statistical analysis. Table 1 and Supplementary Table S1 show the demographic and clinical variables studied at diagnosis and relapse. Post-relapse overall survival time (PROS) was the primary end point, defined as time from first relapse/progression (including relapsed refractory disease) to death or date of last follow-up in survivors. Follow-up was censored at 31 March 2014. KaplanMeier methods were used to calculate estimates of PROS and PRPFS, which is the time between relapse and further relapse/ progression (Kaplan and Meier, 1958). Log-rank tests were used to compare differences in survival estimates between variables. Cox proportional hazards regression analysis was used to investigate risk factors that may influence PROS (Cox, 1972). The associations between PROS and MYCN amplification, 1p deletion, time interval from diagnosis to relapse and age at diagnosis were analysed. Age at diagnosis was categorised into $<18$ months, $\geqslant 18$ months and $<5$ years, $\geqslant 5$ years, since 18 months is now used to stratify patients at diagnosis and there is evidence that older children have a more protracted relapse course (Cohn et al, 2009). Time interval from diagnosis to relapse was categorised as $<6$ months, 6 to $<12$ months, 12 to $<18$ months, 18 to $<24$ months and $\geqslant 24$ months to enable comparison with previously published studies (London et al, 2011; Simon et al, 2011). Two time periods of diagnosis, $\leqslant 2000$ and $>2000$, were used to categorise patients as around this time treatment for highrisk neuroblastoma was intensified (Kohler et al, 2007; Pearson et al, 2008; Ladenstein et al, 2010; Kohler et al, 2013). Only models that met the Cox proportional hazard assumption are presented (Cox, 1972).

Subgroup analyses by risk group were carried out for high risk and intermediate risk (IR) patients using the International Neuroblastoma Risk Group (INRG) definitions and a comparison of survivors vs non-survivors (Cohn et al, 2009). Detailed analysis of unresectable, non-MNA cases was undertaken as this group has varied clinical behaviour (Park et al, 2009; Baker et al, 2010). Where the total number of cases was low, the 95\% Wilson confidence intervals for binomial percentages were calculated. Stata version 12 was used for all analyses, with statistical significance taken to be $P<0.05$ (StataCorp, 2011).

\section{RESULTS}

One hundred eighty-nine cases of relapsed neuroblastoma were identified in this study. A flow diagram showing numbers of patients by risk group is given in Figure 1. For all relapsed cases PROS significantly increased after $2000(P<0.001)$ (Supplementary Figure S1a and Supplementary Figure S1b).

High-risk group. The number of cases analysed for each variable differed depending on the completeness of available data (Table 1 and Supplementary Table S1). At diagnosis, $90 \%$ of cases were treated in a clinical trial or per clinical trial protocol (Supplementary Table S2). The overall response assessment according to the INRC criteria (Brodeur et al, 1993) at the end of first-line treatment was: partial response including very good partial response for 70 out of 139 (50\%) cases and complete response for 30 out of 139 (22\%) cases. At first relapse, 124 out of $159(78 \%)$ of cases relapsed within 2 years of diagnosis and 13 out of $107(12 \%)$ of patients relapsed at the primary site alone. In 60 patients $(38 \%)$ in whom levels of urinary catecholamines were recorded at diagnosis and relapse, 48 (80\%) had raised urinary catecholamines levels at both diagnosis and relapse.

The median PROS time for all high-risk cases was 4.5 months (interquartile range (IQR) 1.9-11.4), which was significantly increased for patients diagnosed after $2000 v s$ before $(P<0.001)$ (Figure 2A and B, Supplementary Figure S2a and Supplementary Figure S2b). Significantly more patients diagnosed after 2000, 60 out of $74(81 \%)$, were treated actively at relapse compared with those who were given palliative radiotherapy or supportive care alone 14 out of $74(19 \%)$; vs 22 out of $64(44 \%) \leqslant 2000)(P=0.03)$. 
Table 1. Patient characteristics at relapse for all cases of relapsed neuroblastoma, high-risk cases, and intermediate risk, stage 3, unresectable, non-MNA cases

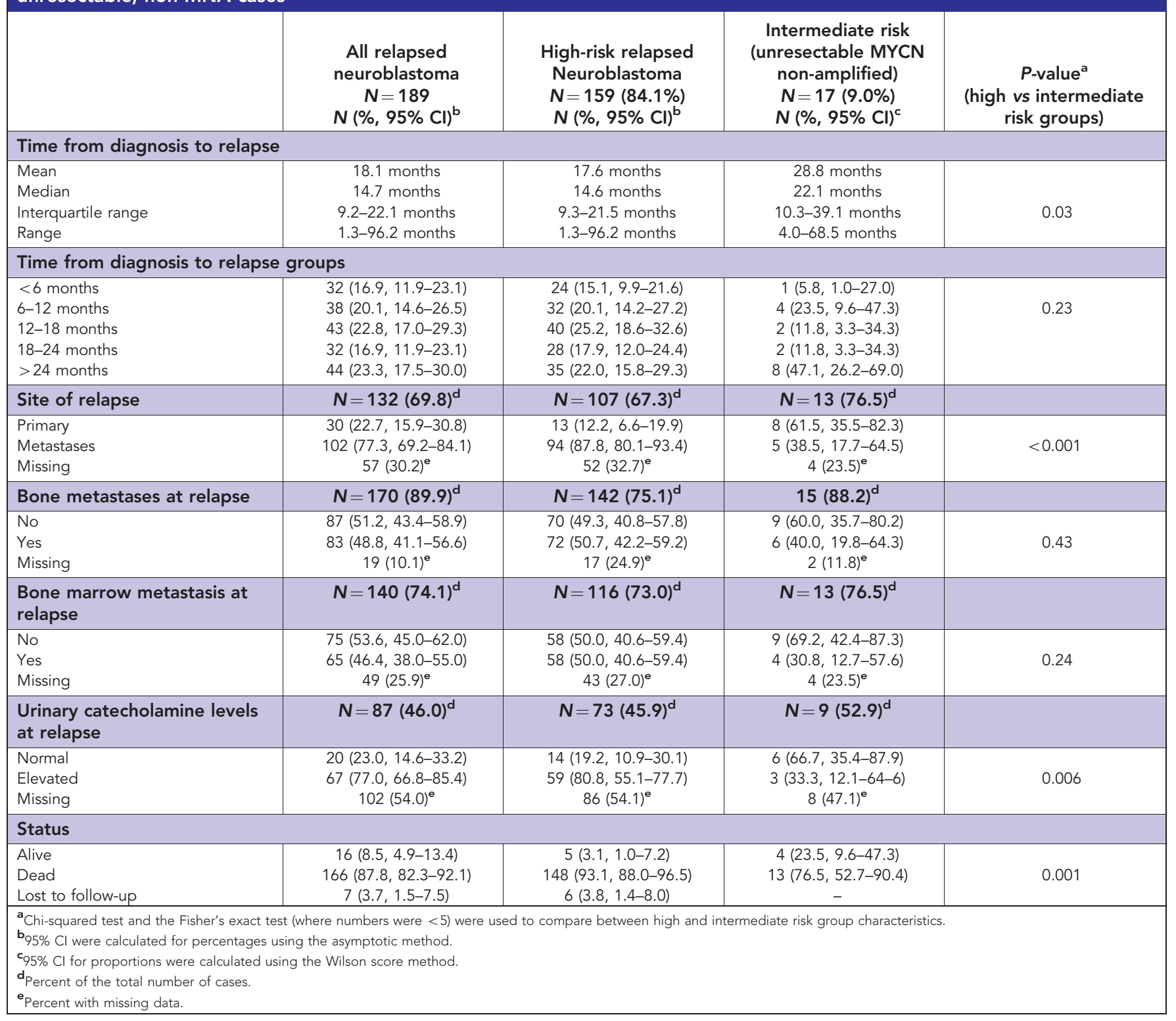

Active treatments at relapse included second-line chemotherapy, mIBG therapy, or second-line chemotherapy followed by other treatments such as radiotherapy, or phase I or II clinical trials in 10 out of $138(7 \%)$ cases (Table 2). Figure 3 shows that for cases diagnosed after 2000, 6 out of 76 (8\%) patients treated by mIBG therapy had a median PROS of 12.2 months (IQR $=10.9-26.2$ months), 5 out of 76 (7\%) patients enrolled onto phase I or II trials had a median PROS of 13.5 months (IQR $=7.7-16.4)$ and 29 out of 76 (38\%) treated by second-line chemotherapy had a median PROS of 6.6 months (IQR =2.5-17.5) compared with 1.5 months $(\mathrm{IQR}=0.6-2.9)$ for cases treated by supportive care $(P=0.01)$. In contrast, before 2000 only one patient had mIBG therapy. For 58 cases, the date of further relapse/progression was recorded and for those patients the median PRPFS was 4.5 months (IQR 2.2-8.7 months); it was 3.9 months (IQR 2.5-8.7 months) for 21 cases diagnosed before 2000 and 4.7 months (IQR 2.1-7.1 months) for 37 cases diagnosed after $2000(P=0.54)$. Treatments received at subsequent relapse/progression are given (Supplementary Table S3).

Cox univariable proportional hazards regression analyses for high-risk cases showed that PROS time was significantly worse for cases with MNA disease $(P<0.0001)$, both MNA and 1p deleted disease $(P=0.02)$, liver metastases at diagnosis $(P=0.02)$, and for cases who relapsed within 6 months of diagnosis compared with relapses $>2$ years $(P=0.03)$, while patients $>5$ years old at diagnosis had longer PROS $(P=0.02)$ (Supplementary Table S4). However, in multivariable analysis only MNA (adjusted $\mathrm{HR}=2.06 ; 95 \%$ CI 1.22-3.46, $P=0.007$ ) and bone marrow metastases at diagnosis (adjusted HR $=2.33$; 95\% CI $1.26-4.29, P=0.007$ ) were independently significantly associated with worse PROS (Table 3). Information on MYCN status was unknown for $30 \%$ of cases, so sensitivity analysis was carried out to include the MYCN unknown cases as an additional category in the model, which showed that it did not affect the results. MNA disease was significantly associated with worse PROS $(P<0.001)$ (Figure $2 \mathrm{C}$ and Supplementary Figure S2c). Similar results were obtained for PROS for cases diagnosed before $(P<0.001)$ (Figure 2D) or after $2000(P=0.02)$ (Figure 2E).

Intermediate risk, unresectable, $M Y C N$ non-amplified group. The number of cases analysed for each variable differed depending on the completeness of available data (Table 1 and Supplementary 


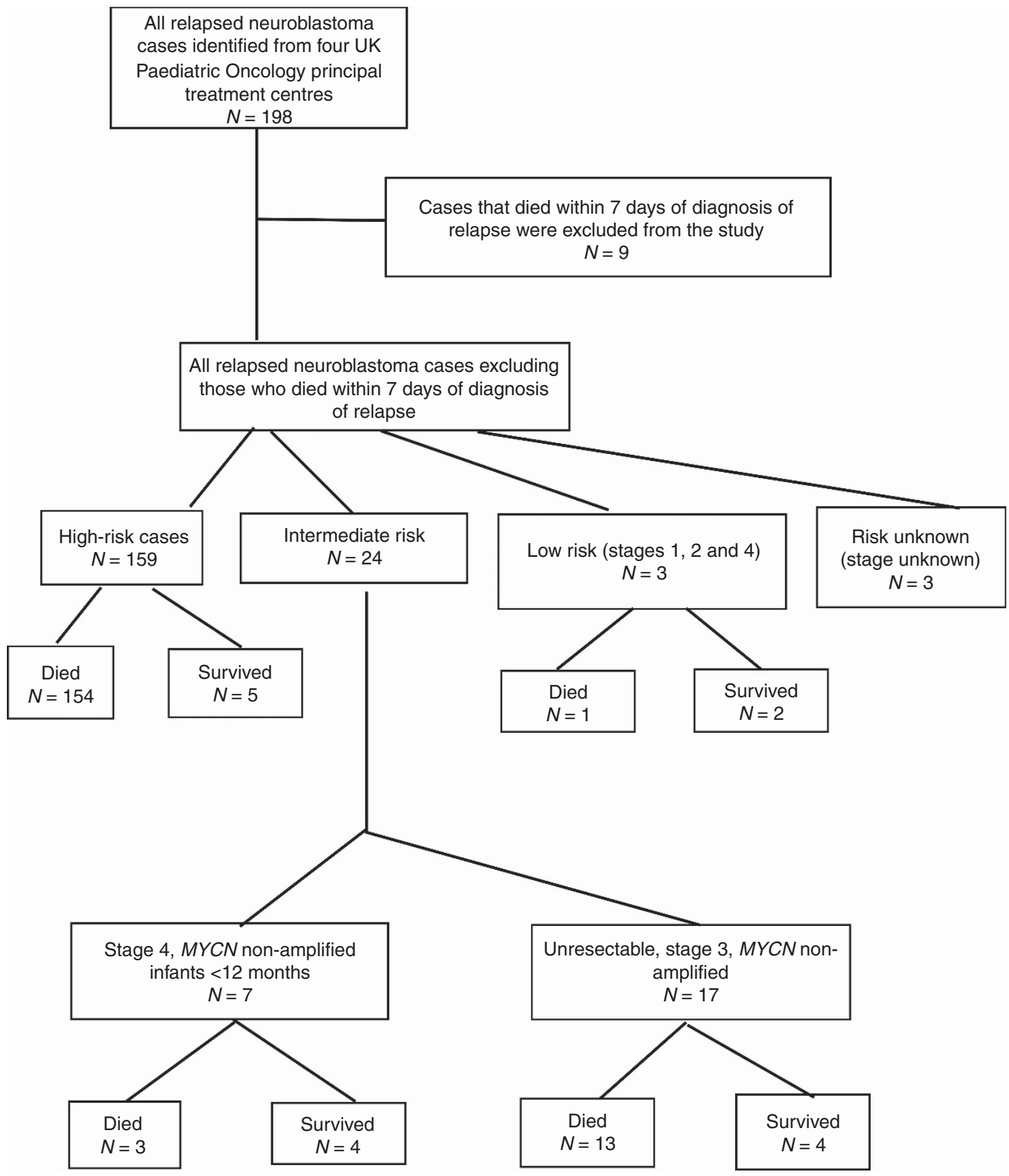

Figure 1. Flow diagram showing number of cases included in the study.

Table S1). The International Neuroblastoma Pathology Classification (INPC) histology (Shimada et al, 1999) was unfavourable in 13 out of 15 (87\%; 95\% CI 62-96\%) cases and primary tumour site was abdominal in 14 out of 17 (82\%; 95\% CI 59-94\%), 12 out of 17 (71\%; 95\% CI 47-87\%) were treated in a clinical trial at diagnosis or per clinical trial protocol (four cases in European Neuroblastoma Study group Fifth study (ENSG5) (Pearson et al, 2008), two cases in European High Risk Neuroblastoma Study 1 of SIOPEurope (HRNBL1) (Ladenstein et al, 2010), two in unresectable NB2009 (Kohler et al, 2013), four in ENSG9 (ClinicalTrials.gov identifier: NCT00276731; Supplementary Table S2). At the end of treatment 7 out of 15 (47\%; 95\% CI 25-70\%) cases had achieved partial response and 6 out of 15 (40\%; 95\% CI 20-64\%) complete response. The median PROS time for this group was 11.8 months $(\mathrm{IQR}=9.0-51.6)$ (Supplementary Figure S3a and b).

Significantly more cases relapsed $>2$ years from diagnosis 8 out of 17 (47\%; 95\% CI 26-69\%) compared with high-risk cases
35 out of 159 (22\%; 95\% CI 16-29; $P=0.04)$. Eight out of thirteen (62\%; $95 \%$ CI $36-82 \%)$ relapsed at the primary site. In 9 out of 17 patients $(53 \%, 31-74 \%)$ in whom levels of urinary catecholamines were recorded at diagnosis and relapse, 3 out of 9 (33\%; 95\% CI $12-$ $65 \%$ ) had raised urinary catecholamine levels at both diagnosis and relapse. Eleven out of sixteen patients (69\%; 95\% CI 44-86\%) were treated with second-line high-risk type chemotherapy at first relapse (Table 2). A further relapse/progression date and treatment were recorded for eight cases, and for those the median PRPFS was 10.1 months (IQR $=7.8-12.3$ months). Five out of eight (63\%; 95\% CI $31-86 \%)$ were treated with second line chemotherapy and the remainder treated by combined chemotherapy and surgery or radiotherapy including $\mathrm{mIBG}$ therapy or supportive care (Supplementary Table S3).

Survivors. Only $8 \%$ of all relapsed patients in our study survived to the end of the study period (Supplementary Table S5). Fifteen 
A

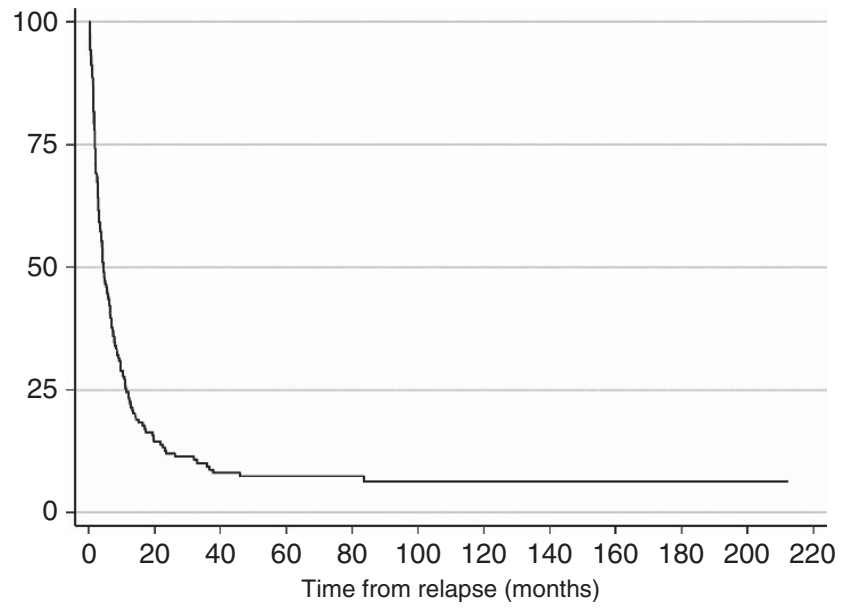

C

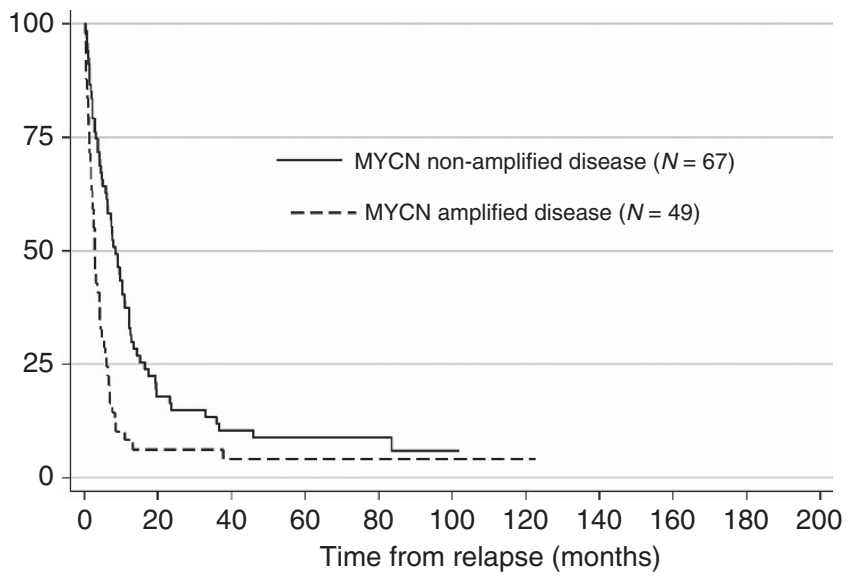

B

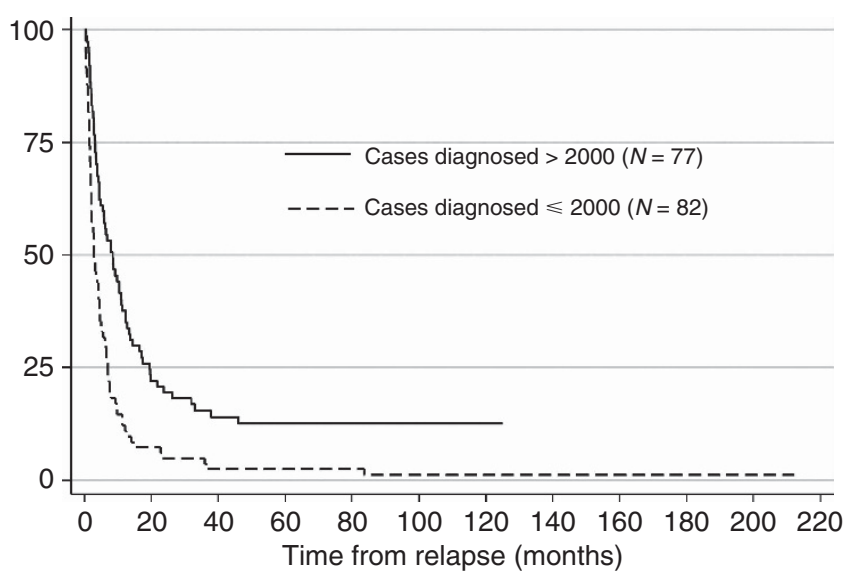

D

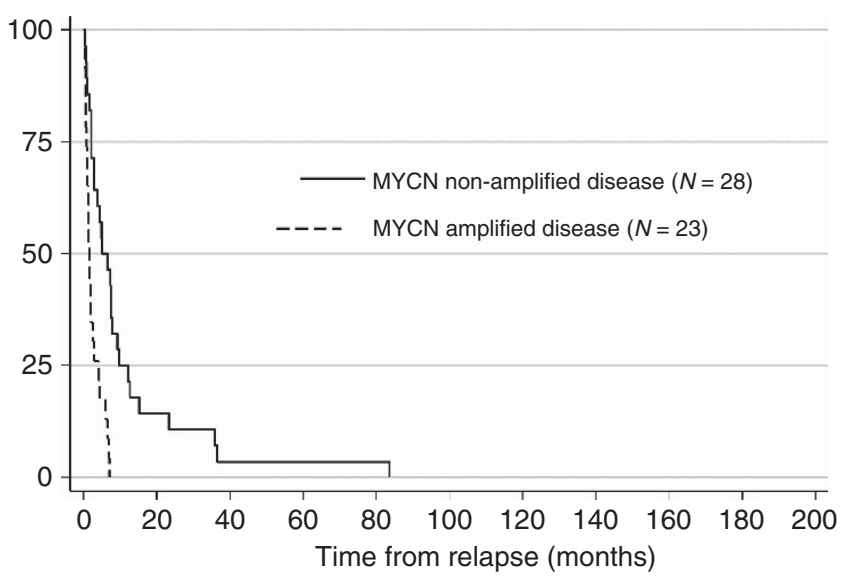

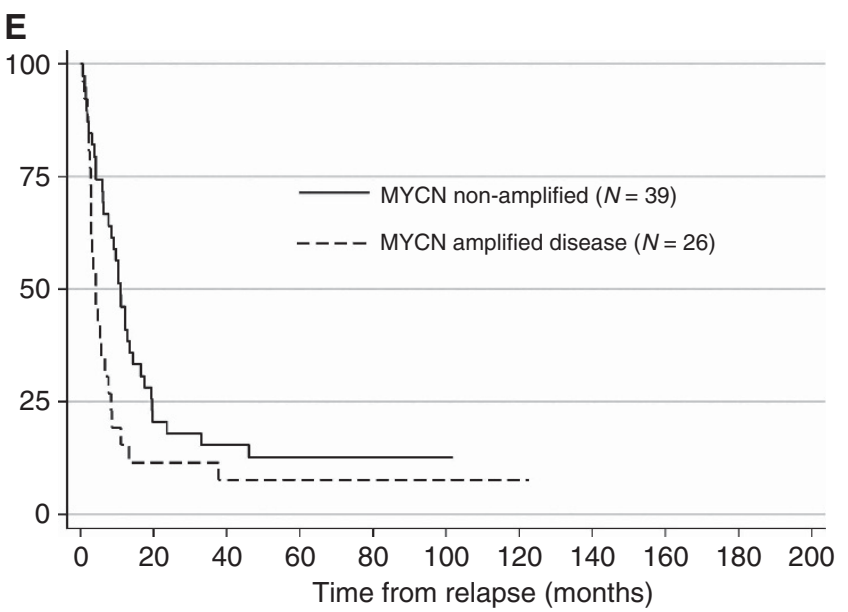

Figure 2. Kaplan-Meier graphs for post-relapse overall survival time for the high-risk group $(N=159)$. (A) Post relapse overall survival (PROS) time. Median PROS time for high-risk cases was 4.5 months (IQR=1.9-11.4). Five-year PROS for high-risk cases was 7.4\% (95\% Cl 4.0-12.1\%). (B) Post-relapse overall survival by year of diagnosis. Median PROS time was 2.9 months (IQR 1.4-6.9) for cases diagnosed $\leqslant 2000$ vs 8.4 months (IQR 3.0-17.4) for cases diagnosed $>2000$ ( $P<0.001)$. Five-year PROS for high-risk cases diagnosed $\leqslant 2000$ was $2.4 \%(95 \%$ Cl 0.5-7.7\%) vs $12.7 \%$ (95\% $\mathrm{Cl}$ 6.4-21.2\%) for cases diagnosed > 2000. (C) PROS by MYCN status. Median PROS time was 2.9 months (95\% Cl 2.0-4.3) for MYCN amplified vs 8.5 months for MYCN non-amplified (95\% Cl 5.9-11.1; $P<0.001)$. Five-year PROS for MYCN non-amplified cases was $9.0 \%$ (95\% Cl 3.7-17.2\%) vs $4.1 \%$ (95\% Cl 0.8-12.3\%) for MYCN amplified cases. (D) PROS for cases diagnosed $\leqslant 2000$ by MYCN status. For cases diagnosed $\leqslant 2000$, the median PROS for MYCN amplified disease was 1.5 months (95\% Cl 0.9-2.7) vs 5.1 months (95\% Cl 2.9-7.9) for MYCN non-amplified cases $(P<0.001)$. Five year PROS for MYCN non-amplified was 3.6\% (95\% Cl 0.3-15.4\%) vs $0 \%$ for MYCN amplified cases. (E) PROS for cases diagnosed $>2000$ by MYCN status. For cases diagnosed > 2000, the median PROS for MYCN amplified disease was 4.3 months (95\% Cl 2.9-6.6) vs 10.9 months (95\% Cl 6.3-14.4) for MYCN non-amplified ( $P=0.02)$. Five-year PROS for MYCN non-amplified cases was $12.8 \%(95 \% \mathrm{Cl} 4.7-25.2 \%)$ vs 7.7\% (95\% Cl 1.3-21.7\%) for MYCN amplified cases. 
out of sixteen patients (8\%; 95\% CI 72-99\%) were disease free 5 years from first relapse. Four out of five of the high-risk survivors and 1 out of 4 of the IR were diagnosed $>2000$. The median follow-up time from relapse for survivors was 11 years (IQR 6.6-16.5).
Eight out of sixteen (50\%; 95\% CI 28-72\%) patients were aged $\leqslant 18$ months at diagnosis, 5 out of 15 (33\%; 95\% CI 15-58\%) had high-risk disease at diagnosis and 12 out of 13 (85\%; 95\% CI 58-96\%) were non-MNA. At relapse, 8 out of 14 (57\%; 95\% CI 33-79\%)

Table 2. Treatment received at first relapse for all relapsed neuroblastoma cases, high risk cases and intermediate risk, stage 3, unresectable, non-MNA neuroblastoma

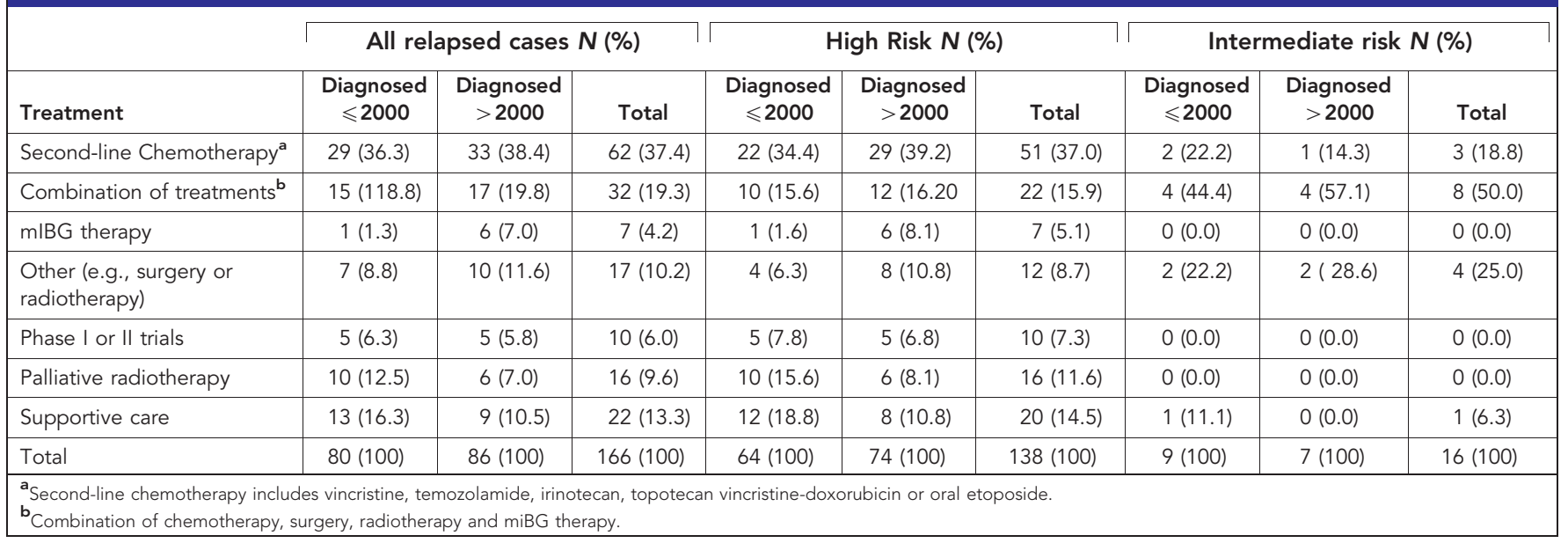

High risk relapsed neuroblastoma cases $(N=159)$

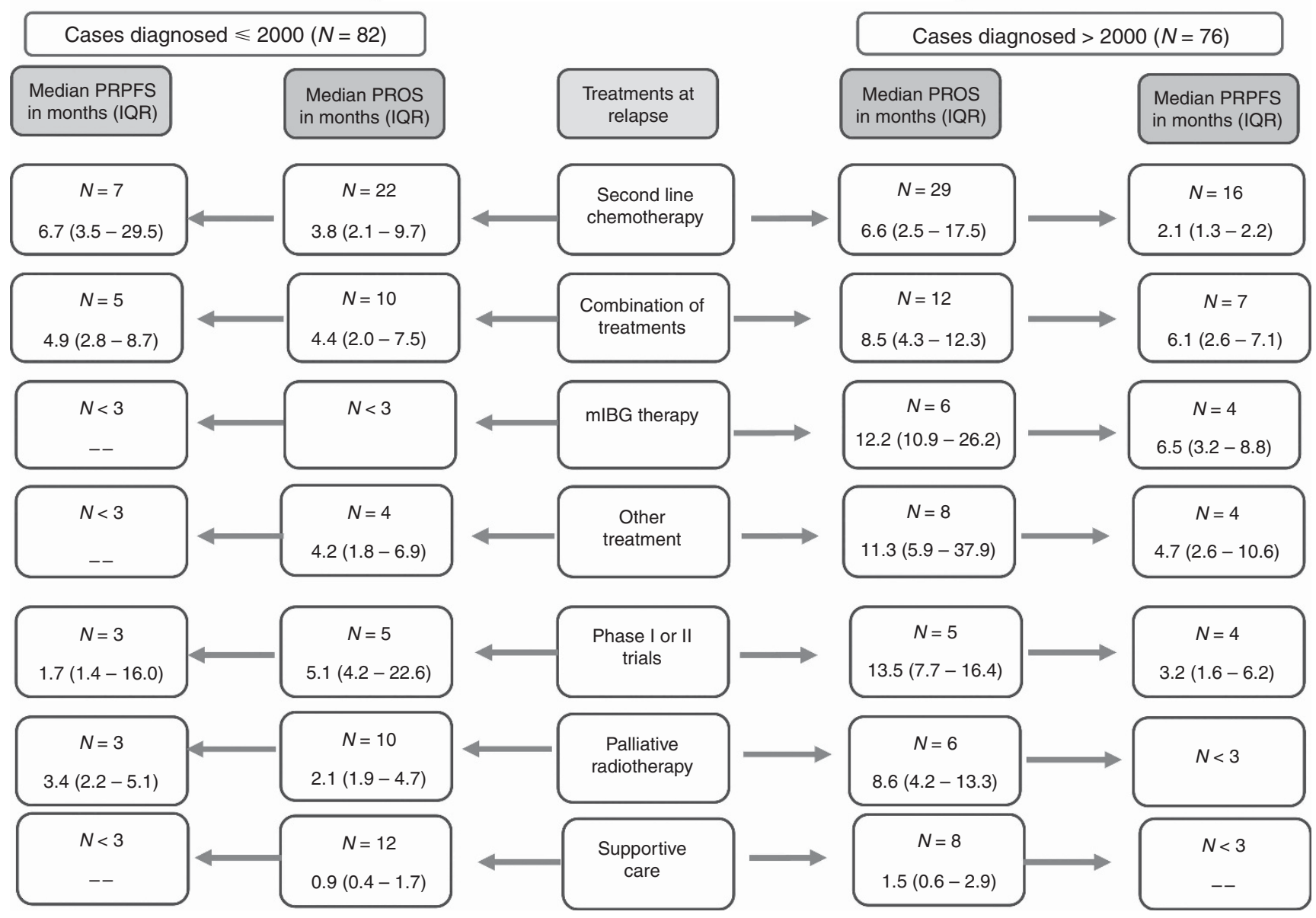

Figure 3. Flow diagram showing treatments that high-risk patients received at first relapse and its outcome. Abbreviations: PROS $=$ postrelapse overall survival; IQR = interquartile range; PRPFS = post-relapse progression-free survival. 
Table 3. Results of multivariable analysis for post-relapse overall survival for high-risk cases

\begin{tabular}{|c|c|c|c|}
\hline Factor & $N(\%)$ & Hazard ratio $(95 \% \mathrm{Cl})$ & $P$-value \\
\hline \multicolumn{4}{|c|}{ Age at diagnosis } \\
\hline $\begin{array}{l}\leqslant 5 \text { years } \\
>5 \text { years }\end{array}$ & $\begin{array}{r}126(79.3) \\
33(20.7)\end{array}$ & $\begin{array}{c}1 \\
0.77(0.44-1.34)\end{array}$ & 0.35 \\
\hline $\begin{array}{l}\text { No } \\
\text { Yes }\end{array}$ & $\begin{array}{r}26(17.8) \\
120(82.2)\end{array}$ & $\begin{array}{c}1 \\
2.33(1.26-4.29)\end{array}$ & 0.007 \\
\hline \multicolumn{4}{|c|}{ Liver metastases at diagnosis } \\
\hline \multicolumn{4}{|c|}{ MYCN disease } \\
\hline $\begin{array}{l}\text { Not amplified } \\
\text { Amplified }\end{array}$ & $\begin{array}{l}67(57.8) \\
49(42.2)\end{array}$ & $\begin{array}{c}1 \\
2.06(1.22-3.46)\end{array}$ & 0.007 \\
\hline \multicolumn{4}{|c|}{ Time from diagnosis to relapse } \\
\hline $\begin{array}{l}>24 \text { months } \\
18-24 \text { months } \\
12-18 \text { months } \\
6-12 \text { months } \\
<6 \text { months }\end{array}$ & $\begin{array}{l}35(22.0) \\
28(17.9) \\
40(25.2) \\
32(20.1) \\
24(15.1)\end{array}$ & $\begin{array}{c}1 \\
1.18(0.58-2.40) \\
1.21(0.65-2.24) \\
1.22(0.65-2.31) \\
1.52(0.76-3.01)\end{array}$ & $\begin{array}{l}0.65 \\
0.54 \\
0.54 \\
0.24\end{array}$ \\
\hline
\end{tabular}

survivors were treated with second-line chemotherapy, and/or with radiotherapy and surgery and 1 out of 14 was treated with chemotherapy and autologous stem cell transplant.

Comparing survivors with non-survivors showed that $27 \%$ (95\% CI $11-52 \%)$ of survivors had favourable INPC histology compared with $4 \%$ (95\% CI $1-8 \%)$ of non-survivors $(P=0.006)$, $93 \%$ (95\% CI 70-99\%) of survivors had complete or partial overall response at end of treatment compared with $71 \%$ of non-survivors (95\% CI $64-79 \% ; P=0.04)$, and $50 \%$ relapsed $>2$ years from diagnosis compared with $21 \%$ (95\% CI 15-28\%) of non-survivors $(P=0.01)$ (Supplementary Table S6). Of the high-risk survivors, 3 out of 5 were $\geqslant 18$ months at diagnosis, 4 out of 5 relapsed after initial myeloablative therapy and 1 out of 5 relapsed after surgery.

\section{DISCUSSION}

This study was designed to gain knowledge about relapsed neuroblastoma from primary sources of information and to reflect the outcome of these patients, avoiding the selection bias of clinical trials. It is the first multi-institutional study to report on PRPFS which is a very useful parameter for judging the efficacy of early phase clinical trials. The observed interval between relapses is important for early phase trials design as it provides a baseline comparator for exploratory studies of new agents in relapsed neuroblastoma, where the time interval of PRPFS can be used as a primary endpoint when designing exploratory trials (Santana et al, 2008; Fox et al, 2014).

The current study reports the demographics of relapsed neuroblastoma cases diagnosed during 1990-2010 from four UK Paediatric Oncology principal treatment centres treating around $30 \%$ of all UK patients in total. PROS time remains very poor for both high risk and IR (unresectable, non-MNA) disease. The median PROS for high-risk cases was 4.5 months with only $7 \%$ of relapsed cases surviving more than 5 years. However, PROS has significantly increased for high-risk cases diagnosed after the year 2000 compared with before 2000 from 2.9 months to 8.4 months, achieving a 5 -year survival of $12.7 \%$. This significant improvement in PROS after 2000 may be due to more patients being treated actively at relapse with second line chemotherapy such as temozolomide, topotecan, irinotecan or oral etoposide. All these chemotherapy regimens increase the PRPFS, but long-term overall survival remains poor (Rubie et al, 2006; London et al, 2010; Bagatell et al, 2011; Fox et al, 2014).

High risk. In contrast to most previous epidemiological studies of relapsed neuroblastoma, our study reports second relapses. The duration from first to subsequent relapse is important particularly for early phase clinical trial design. For a sub-group of patients, the date of a second event was recorded and the median PRPFS time to second event was 4.5 months (IQR $=2.2-8.7$ ). This is shorter than that reported by Santana and colleagues, who found a median disease progression-free interval of 7.2 months between first and second relapse (Santana et al, 2008). This may reflect a difference in treatments given, as very few patients in our cohort were treated on phase I or II clinical trials at first or subsequent relapse, partly due to a lack of available applicable trials before 2000 (Moreno et al, 2013). Recently trials for relapsed neuroblastoma have opened across Europe, such as the BEACON study, a randomised phase II trial exploring the use of bevacizumab and temozolomide or temozolomide-irinotecan (ClinicalTrials.gov identifier: NCT02308527). The results of our study demonstrating the very poor outcomes following relapse strongly argue for the inclusion of patients with high risk relapsed neuroblastoma in randomised clinical trials at relapse whenever possible. This study does not identify a specific group of patients who are less likely to benefit from further treatment at relapse.

Our results for PROS concur with those published using data from the INRG database (2226 relapsed cases), diagnosed during 1990-2002, where 5-year PROS for stage 4 cases, $>18$ months with non-MNA disease was $8 \%$, and only $4 \%$ for stage 4 with MNA disease (London et al, 2011). Around 55 out of 189 (29\%) cases from the present study may overlap with the INRG database. A study from the Italian neuroblastoma registry reported 10-year PROS for stage 4 disease at diagnosis was $1.5 \%$ following progression and 2\% following relapse (Garaventa et al, 2009). Analysis of relapsed high-risk neuroblastoma patients from German trials diagnosed during1990-2007, treated with secondline chemotherapy at relapse, found 3-year PROS was 9.6\% (Simon et al, 2011).

Several prognostic factors are used in risk stratification for neuroblastoma at diagnosis including age at diagnosis, MNA, presence of segmental chromosomal aberrations, metastatic disease and tumour histology (George et al, 2001). These factors may also be important in determining response to treatments at relapse. Age $>5$ years at 
diagnosis had a longer PROS consistent with studies showing that older children have a more protracted relapse course (Cohn et al, 2009). We also found worse PROS in high-risk cases with MYCN amplification as previously reported (Lau et al, 2004; Garaventa et al, 2009; London et al, 2011; Simon et al, 2011), and with both MNA and chromosome $1 \mathrm{p}$ deletion at diagnosis. Chromosome $1 \mathrm{p}$ deletion has been shown to be associated with shorter median PROS (Lau et al, 2004; London et al, 2011), poorer event-free survival from diagnosis (EFS) (Maris et al, 2001), and to be strongly related to high-risk features (Attiyeh et al, 2005). Both 1p deletion and 11q loss were independently associated with shorter PRPFS in patients with low and IR disease (Attiyeh et al, 2005). However, in the present study insufficient data on 11q or other segmental chromosomal abnormalities precluded formal analysis. Interestingly, liver metastases at diagnosis were also associated with shorter PROS in our study. In previous studies, liver metastases were associated with MNA and had a worse prognosis in older children (DuBois et al, 1999), unlike infants with non-MNA disease (Kushner et al, 2006). Ninety percent of all relapsed cases we studied had primary tumours arising in abdominal sites and only $8 \%$ had thoracic or neck tumours. This is in-keeping with other studies reporting that adrenal tumours are associated with unfavourable clinical and biological characteristics and therefore worse EFS in contrast to thoracic tumours which are associated with favourable characteristics and better EFS (Sung et al, 2009; Vo et al, 2014). However, we acknowledge the small numbers of cases involved in this study and the missing data in some of the variables means some results should be interpreted with caution.

The duration from diagnosis to first relapse has been shown to be a prognostic factor for PROS (Lau et al, 2004; Garaventa et al, 2009; London et al, 2011). Around $80 \%$ of high-risk cases in our study relapsed within 2 years from diagnosis, and PROS was significantly shorter when relapse occurred within 6 months of diagnosis. Lau and colleagues found that patients who relapsed either within 6 months from diagnosis or 6 months from stem cell transplant had shorter median PROS (Lau et al, 2004). Other studies, however, reported recurrence within 6-24 months from diagnosis implied worse PROS (London et al, 2011; Simon et al, 2011). These differences may be due to patient heterogeneity; some studies included only high-risk cases (Simon et al, 2011), whereas others included all relapsed neuroblastoma (London et al, 2011), or different definitions of relapse.

The role of urinary catecholamines as a reliable marker for monitoring neuroblastoma relapse is controversial (Simon et al, 2003). They may be negative due to small tumour burden at relapse or decreased production in some previously treated neuroblastomas. In the present study, urinary catecholamines were raised at relapse in $80 \%$ of patients who had raised catecholamines at diagnosis, but were only measured in $46 \%$ of patients at relapse. The current study suggests that raised urinary catecholamines are helpful as a confirmatory indicator and a tumour marker of response (Kushner et al, 2009).

Intermediate risk. IR disease comprised $13 \%$ of relapsed neuroblastomas in our study, $4 \%$ who were IR stage 4 , non-MNA $<12$ months old were not further analysed as this subgroup is usually salvageable at relapse (Maris et al, 2007; De Bernardi et al, 2009). However, 9\% were IR, unresectable, non-MNA with mostly unfavourable INPC histology. The prognostic value of pathology in this group was confirmed in a recent SIOPEN study (Kohler et al, 2013). Analysis of stage 3 data from the INRG database showed that patients $>18$ months with undifferentiated INPC histology and elevated levels of serum ferritin had worse overall survival and EFS (Meany et al, 2014). In the absence of MYCN amplification other genetic markers in this group may be important risk factors, such as tumour cell ploidy (Bagatell et al, 2005; Baker et al, 2010), 11q aberrations (Attiyeh et al, 2005; Meany et al, 2014) or other segmental chromosomal abnormalities (Defferrari et al, 2015). The management of this group of patients remains controversial, those with unfavourable histological or biological features are treated with intensive multimodality therapy including myeloablative therapy in the United States (Baker et al, 2010), but not in the United Kingdom or Europe. However, in the present study 6 out of 17 patients (35\%; 95\% CI 17-59\%) were treated in high-risk protocols (ENSG5 and HRNBL1) at the physician's discretion due to patient age and/or unknown MYCN status. Almost 50\% of IR, unresectable, non-MNA neuroblastoma relapsed $>2$ years from diagnosis including 5 out of 17 (29\%; 95\% CI 13-53\%) patients who had local radiotherapy as part of their frontline treatment at diagnosis. Salvage therapies at relapse failed in $75 \%$ of cases, suggesting the need for intensification of upfront treatment regimens for cases with unfavourable histology at diagnosis (Kohler et al, 2013), to determine whether their use would diminish the likelihood of relapse.

\section{CONCLUSION}

In conclusion, this study showed that the PROS for neuroblastoma patients has increased but long-term survival remains poor. Eighty percent of high-risk relapses occur within 2 years from diagnosis, in contrast to only $50 \%$ of IR unresectable, non-MNA neuroblastoma, and although this latter group comprise $<10 \%$ of all relapsed neuroblastoma, the failure to salvage these patients in over $75 \%$ of cases, even when given high-risk-type treatment at relapse, is concerning. Since MNA disease has a worse OS as highlighted by previous studies, our study underscores the need for early phase clinical trial data to be analysed according to $M Y C N$ status. Finally, more patients need to be recruited to early phase studies where PRPFS should be considered as the primary endpoint in study design, especially if cytostatic novel therapies are given.

\section{ACKNOWLEDGEMENTS}

The study received ethical approval from the Newcastle and North Tyneside 2 Research Ethics Committee (REC reference number 10/H0907/40) dated 25 August 2010. We are very grateful to Cancer Research UK, grant number C8561/A12084 and the North of England Children's Cancer Research Fund (NECCRF) for providing financial support for $\mathrm{NOB}$ and $\mathrm{PWJ}$, to the data managers at Manchester, Leeds, Newcastle and Marsden Hospitals, to Dr Danielle Ingham for data extraction and to Mr Richard Hardy, funded by the NECCRF, for providing IT support. We thank Cancer Research UK, the UK Department of Health and Neuroblastoma UK for funding the national neuroblastoma genetic reference centre. We also thank The Great North Children's Hospital Newcastle upon Tyne Hospitals NHS Foundation Trust, the Leeds Teaching Hospitals NHS Trust, the Royal Manchester Children's Hospital and The Royal Marsden NHS Foundation Trust. ADJP is funded through a Cancer Research UK Life Chair and Programme Grant included within a Cancer Research UK ICR Core Award (C347/A15403) and is supported from the NIHR RM/ ICR Biomedical Research Centre. The Northern Region Young Persons Malignant Disease Registry is funded by the Newcastle upon Tyne Hospitals NHS Foundation Trust, The Yorkshire Specialist Register of Cancer in Children and Young People is funded by the Candlelighters Trust and The Manchester Children's Tumour Registry was funded by Cancer Research UK. We acknowledge the support of the National Institute for Health Research Clinical Research Network: Cancer (UKCRNID10308). 


\section{CONFLICT OF INTEREST}

Dr Lucas Moreno discloses the following activities: consultancy/ advisory board participation for Novartis, AstraZeneca, RocheGenentech, Mundipharma and Bayer. The remaining authors declare no conflict of interest.

\section{REFERENCES}

Attiyeh EF, London WB, Mossé YP, Wang Q, Winter C, Khazi D, McGrady PW, Seeger RC, Look AT, Shimada H, Brodeur GM, Cohn SL, Matthay KK, Maris JM. Children's Oncology Group (2005) Chromosome 1p and 11q deletions and outcome in neuroblastoma. N Engl J Med 353: 2243-2253.

Bagatell R, Rumcheva P, London WB, Cohn SL, Look AT, Brodeur GM, Frantz C, Joshi V, Thorner P, Rao PV, Castleberry R, Bowman LC (2005) Outcomes of children with intermediate-risk neuroblastoma after treatment stratified by MYCN status and tumor cell ploidy. J Clin Oncol 23: $8819-8827$.

Bagatell R, London WB, Wagner LM, Voss SD, Stewart CF, Maris JM, Kretschmar C, Cohn SL (2011) Phase II study of irinotecan and temozolomide in children with relapsed or refractory neuroblastoma: a Children's Oncology Group study. J Clin Oncol 29: 208-213.

Baker DL, Schmidt ML, Cohn SL, Maris JM, London WB, Buxton A, Stram D, Castleberry RP, Shimada H, Sandler A, Shamberger RC, Look AT, Reynolds CP, Seeger RC, Matthay KK. Children's Oncology Group (2010) Outcome after reduced chemotherapy for intermediate-risk neuroblastoma. N Engl J Med 363: 1313-1323.

Birch JM (1988) Manchester children's tumour registry 1954-1970 and 1971-1983. In International Incidence of Childhood Cancer, Parkin DM, Stiller CA, Draper GJ, Bieber CA, Terracini B, Young JL (eds). 299-304. IARC: Lyon.

Brodeur GM, Pritchard J, Berthold F, Carlsen NL, Castel V, Castelberry RP, De Bernardi B, Evans AE, Favrot M, Hedborg F (1993) Revisions of the international criteria for neuroblastoma diagnosis, staging, and response to treatment. J Clin Oncol 11: 1466-1477.

Canete A, Gerrard M, Rubie H, Castel V, Di Cataldo A, Munzer C, Ladenstein R, Brichard B, Bermúdez JD, Couturier J, de Bernardi B, Pearson AJ, Michon J (2009) Poor survival for infants with $M Y C N$-amplified neuroblastoma despite intensified treatment: the International Society of Paediatric Oncology European Neuroblastoma Experience. J Clin Oncol 27: 1014-1019.

ClinicalTrials.gov identifier: NCT00276731. Combination Chemotherapy Followed by Surgery With or Without Radiation Therapy in Treating Young Patients With Stage II or Stage III Neuroblastoma. UKCCSGENSG-9.

ClinicalTrials.gov identifier: NCT02308527. A Randomised Phase IIb Trial of Bevacizumab Added to Temozolomide \pm Irinotecan for Children With Refractory/Relapsed Neuroblastoma-BEACON-Neuroblastoma Trial.

Cohn SL, Tweddle DA (2004) MYCN amplification remains prognostically strong 20 years after its 'clinical debut'. Eur J Cancer 40: 2639-2642.

Cohn SL, Pearson AD, London WB, Monclair T, Ambros PF, Brodeur GM, Faldum A, Hero B, Iehara T, Machin D, Mosseri V, Simon T, Garaventa A, Castel V, Matthay KK (2009) The International Neuroblastoma Risk Group (INRG) classification system: An INRG Task Force report. J Clin Oncol 27: 289-297.

Cotterill SJ, Parker L, Malcolm AJ, Malcolm AJ, Reid M, More L, Craft AW (2000) Incidence and survival for cancer in children and young adults in the North of England, 1968-1995: a report from the Northern Region Young Persons' Malignant Disease Registry. Br J Cancer 83: 397-403.

Cox DR (1972) Regression models and life-tables. J Royal Statist Soc Ser B 34: $187-220$.

De Bernardi B, Gerrard M, Boni L, Rubie H, Canete A, Di Cataldo A, Castel V, Forjaz de Lacerda A, Ladenstein R, Ruud E, Brichard B, Couturier J, Ellershaw C, Munzer C, Bruzzi P, Michon J, Pearson AD (2009) Excellent outcome with reduced treatment for infants with disseminated neuroblastoma without MYCN gene amplification. J Clin Oncol 27: 1034-1040.

Defferrari R, Mazzocco K, Ambros IM, Ambros PF, Bedwell C, Beiske K, Bénard J, Berbegall AP, Bown N, Combaret V, Couturier J, Erminio G, Gambini C, Garaventa A, Gross N, Haupt R, Kohler J, Jeison M, Lunec J, Marques B, Martinsson T, Noguera R, Parodi S, Schleiermacher G, Tweddle DA, Valent A, Van Roy N, Vicha A, Villamon E, Tonini GP
(2015) Influence of segmental chromosome abnormalities on survival in children over the age of 12 months with unresectable localized peripheral neuroblastic tumours without $M Y C N$ amplification. Br J Cancer 112: 290-295.

DuBois SG, Kalika Y, Lukens JN, Brodeur GM, Seeger RC, Atkinson JB, Haase GM, Black CT, Perez C, Shimada H, Gerbing R, Stram DO, Matthay KK (1999) Metastatic sites in stage IV and IVS neuroblastoma correlate with age, tumor biology, and survival. J Pediatr Hematol Oncol 21: $181-189$.

Feltbower RG, Picton S, Bridges LR, Crooks DA, Glaser AW, McKinney PA (2004) Epidemiology of central nervous system tumours in children and young adults (0-29 years) Yorkshire, United Kingdom. Pediatr Hematol Oncol 21: 647-660.

Fox E, dMosse' YP, Meany HM, Gurney JG, Khanna G, Jackson HA, Gordon G, Shusterman S, Park JR, Cohn SL, Adamson PC, London WB, Maris JM, Balis FM (2014) Time to disease progression in children with relapsed or refractory neuroblastoma treated with ABT-751: a report from the Children's Oncology Group (ANBL0621). Pediatr Blood Cancer 61: 990-996.

Garaventa A, Parodi S, De Bernardi B, De Bernardi B, Dau D, Manzitti C, Conte M, Casale F, Viscardi E, Bianchi M, D’Angelo P, Zanazzo GA, Luksch R, Favre C, Tamburini A, Haupt R (2009) Outcome of children with neuroblastoma after progression or relapse. A retrospective study of the Italian neuroblastoma registry. Eur J Cancer 45: 2835-2842.

Gatta G, Botta L, Rossi S, Aareleid T, Bielska-Lasota M, Clavel J, Dimitrova N, Jakab Z, Kaatsch P, Lacour B, Mallone S, Marcos-Gragera R, Minicozzi P, Sánchez-Pérez MJ, Sant M, Santaquilani M, Stiller C, Tavilla A, Trama A, Visser O, Peris-Bonet R. EUROCARE Working Group (2014) Childhood cancer survival in Europe 1999-2007: results of EUROCARE-5-a population-based study. Lancet Oncol 15: 35-47.

George RE, Variend S, Cullinane C, Cotterill SJ, McGuckin AG, Ellershaw C, Lunec J, Pearson AD. United Kingdom Children Cancer Study Group (2001) Relationship between histopathological features, MYCN amplification, and prognosis: a UKCCSG study United Kingdom Children Cancer Study Group. Med Pediatr Oncol 36: 169-176.

Kaplan EL, Meier P (1958) Non-parametric estimation from incomplete observations. JASA 53: 457-481.

Kohler JA, Ellershaw C, Machin D. Neuroblastoma Working Group of the Children's Cancer and Leukaemia Group (2007) Response to N7 induction chemotherapy in children more than one year of age diagnosed with metastatic neuroblastoma treated in UKCCSG centers. Pediatr Blood Cancer 49: 234-239.

Kohler JA, Rubie H, Castel V, Beiske K, Holmes K, Gambini C, Casale F, Munzer C, Erminio G, Parodi S, Navarro S, Marquez C, Peuchmaur M, Cullinane C, Brock P, Valteau-Couanet D, Garaventa A, Haupt R (2013) Treatment of children over the age of one year with unresectable localised neuroblastoma without MYCN amplification: results of the SIOPEN study. Eur J Cancer 49: 3671-3679.

Kushner BH, Kramer K, LaQuaglia MP, Modak S, Cheung NK (2006) Liver involvement in neuroblastoma: the Memorial Sloan-Kettering Experience supports treatment reduction in young patients. Pediatr Blood Cancer 46: 278-284.

Kushner BH, Kramer K, Modak S, Cheung NK (2009) Sensitivity of surveillance studies for detecting asymptomatic and unsuspected relapse of high-risk neuroblastoma. J Clin Oncol 27: 1041-1046.

Ladenstein R, Valteau-Couanet D, Brock P, Yaniv I, Castel V, Laureys G, Malis J, Papadakis V, Lacerda A, Ruud E, Kogner P, Garami M, Balwierz W, Schroeder H, Beck-Popovic M, Schreier G, Machin D, Pötschger U, Pearson A (2010) Randomized trial of prophylactic granulocyte colonystimulating factor during rapid COJEC induction in pediatric patients with high-risk neuroblastoma: the European HR-NBL1/SIOPEN study. J Clin Oncol 28: 3516-3524.

Lau L, Tai D, Weitzman S, Grant R, Baruchel S, Malkin D (2004) Factors influencing survival in children with recurrent neuroblastoma. J Pediatr Hematol Oncol 26: 227-232.

London WB, Frantz CN, Campbell LA, Seeger RC, Brumback BA, Cohn SL, Matthay KK, Castleberry RP, Diller L (2010) Phase II randomized comparison of topotecan plus cyclophosphamide $v s$ topotecan alone in children with recurrent or refractory neuroblastoma: a Children's Oncology Group study. J Clin Oncol 28: 3808-3815.

London WB, Castel V, Monclair T, Ambros PF, Pearson AD, Cohn SL, Berthold F, Nakagawara A, Ladenstein RL, Iehara T, Matthay KK (2011) Clinical and biologic features predictive of survival after relapse of 
neuroblastoma: a report from the International Neuroblastoma Risk Group project. J Clin Oncol 29: 3286-3292.

Maris JM, Guo C, Blake D, White PS, Hogarty MD, Thompson PM, Rajalingam V, Gerbing R, Stram DO, Matthay KK, Seeger RC, Brodeur GM (2001) Comprehensive analysis of chromosome 1p deletions in neuroblastoma. Med Pediatr Oncol 36: 32-36.

Maris JM, Hogarty MD, Bagatell R, Cohn SL (2007) Neuroblastoma. Lancet 369: $2106-2120$.

Maris JM (2010) Recent advances in neuroblastoma. N Engl J Med 362: 2202-2211.

Meany HJ, London WB, Ambros PF, Matthay KK, Monclair T, Simon T, Garaventa A, Berthold F, Nakagawara A, Cohn SL, Pearson AD, Park JR (2014) Significance of clinical and biologic features in stage 3 neuroblastoma: a report from the International Neuroblastoma Risk Group project. Pediatr Blood Cancer 61: 1932-1939.

Moreno L, Marshall LV, Pearson AD (2013) At the frontier of progress for paediatric oncology: the neuroblastoma paradigm. Br Med Bull 108: 173-188.

Park JR, Villablanca JG, London WB, Gerbing RB, Haas-Kogan D, Adkins ES, Attiyeh EF, Maris JM, Seeger RC, Reynolds CP, Matthay KK. Children's Oncology Group (2009) Outcome of high-risk stage 3 neuroblastoma with myeloablative therapy and 13-cis-retinoic acid: a report from the Children's Oncology Group. Pediatr Blood Cancer 52: 44-50.

Park JR, Bagatell R, London WB, Maris JM, Cohn SL, Mattay KK, Hogarty M. COG Neuroblastoma Committee (2013) Children's Oncology Group's 2013 blueprint for research: neuroblastoma. Pediatr Blood Cancer 60: 985-993.

Pearson AD, Pinkerton CR, Lewis IJ, Imeson J, Ellershaw C, Machin D. European Neuroblastoma Study Group; Children's Cancer and Leukaemia Group (CCLG formerly United Kingdom Children's Cancer Study Group) (2008) High-dose rapid and standard induction chemptherapy for patients aged over 1 year with stage 4 neuroblastoma: a randomised trial. Lancet Oncology 9: 247-256.

Pritchard J, Cotterill SJ, Germond SM, Imeson J, de Kraker J, Jones DR (2005) High dose melphalan in the treatment of advanced neuroblastoma: results of a randomized trial (ENSG1) by the European Neuroblastoma Study Group. Pediatr Blood Cancer 44: 348-352.

Rubie H, Chisholm J, Defachelles AS, Morland B, Munzer C, Valteau-Couanet D, Mosseri V, Bergeron C, Weston C, Coze C, Auvrignon A, Djafari L, Hobson
R, Baunin C, Dickinson F, Brisse H, McHugh K, Biassoni L, Giammarile F, Vassal G. Société Françaisedes Cancers de l'Enfant; United Kingdom Children Cancer Study Group-New Agents Group Study (2006) Phase II study of temozolomide in relapsed or refractory high-risk neuroblastoma: a joint Société Française des Cancers de l'Enfant and United Kingdom Children Cancer Study Group-New Agents Group Study. J Clin Oncol 24: 5259-5264.

Santana VM, Furman WL, McGregor LM, Billups CA (2008) Disease control intervals in high-risk neuroblastoma. Cancer 112: 2796-2801.

Shimada H, Ambros IM, Dehner LP, Hata J, Joshi VV, Roald B, Stram DO, Gerbing RB, Lukens JN, Matthay KK, Castleberry RP (1999) The International Neuroblastoma Pathology Classification (the Shimada System). Cancer 86: 364-372.

Simon T, Hero B, Hunneman DH, Berthold F (2003) Tumour markers are poor predictors for relapse or progression in neuroblastoma. Eur J Cancer 39: 1899-1903.

Simon T, Berthold F, Borkhardt A, Kremens B, De Carolis B, Hero B (2011) Treatment and outcomes of patients with relapsed, high-risk neuroblastoma: results of German trials. Pediatr Blood Cancer 56: 578-583.

StataCorp (2011) Stata Statistical Software Release 12. StataCorp LP: College Station, TX.

Stiller CA (2007) Childhood Cancer in Britain: Incidence, Survival, Mortality. Oxford University Press: Oxford, UK.

Sung KW, Yoo KH, Koo HH, Kim JY, Cho EJ, Seo YL, Kim J, Lee SK (2009) Neuroblastoma originating from extra-abdominal sites: association with favorable clinical and biological features. J Korean Med Sci 24: 461-467.

Vo KT, Matthay KK, Neuhaus J, London WB, Hero B, Ambros PF, Nakagawara A, Miniati D, Wheeler K, Pearson AD, Cohn SL, DuBois SG (2014) Clinical, biologic, and prognostic differences on the basis of primary tumor site in neuroblastoma: a report from the international neuroblastoma risk group project. J Clin Oncol 32: 3169-3176.

This work is published under the standard license to publish agreement. After 12 months the work will become freely available and the license terms will switch to a Creative Commons AttributionNonCommercial-Share Alike 4.0 Unported License.

Supplementary Information accompanies this paper on British Journal of Cancer website (http://www.nature.com/bjc) 